\title{
Qualidade microbiológica da água da área de preservação ambiental: Fazenda Guajuviras - Canoas (RS)
}

As áreas úmidas compreendem vários ecossistemas, dentre eles, os banhados, que são locais estratégicos para conservação devido à sua alta diversidade biológica e produtividade resultante das relações estabelecidas entre a água, solo, vegetação e fauna. A Área de Proteção Ambiental (APA) Fazenda Guajuviras está localizada no município de Canoas (RS) e compreende cerca de 560ha. O objetivo desse estudo foi analisar os níveis de contaminação por bactérias heterotróficas e do grupo coliforme, traçar o perfil bioquímico e identificar alguns isolados bacterianos presentes em dois banhados da APA Guajuviras. Para tanto, as coletas foram realizadas em março de 2015, sendo que cada banhado foi dividido em quatro quadrantes, de onde foram coletadas amostras de $250 \mathrm{~mL}$ de água. 0 banhado 2 foi o que apresentou os maiores níveis tanto para coliformes totais como para termotolerantes. Na quantificação das bactérias heterotróficas, os maiores níveis encontrados foram no quadrante norte do banhado 1 e 2 . Foram isoladas oito linhagens bacterianas destes banhados. Das linhagens bacterianas obtidas destes banhados, foi possível a identificação, a partir do sequenciamento do gene $16 \mathrm{~S}$ rRNA, de oito isolados de dois gêneros: Pseudomonas sp. e Serratia sp., e de mais três espécies: Bacillus subtilis, Lactococcus garvieae e Pseudomonas fluorescens.

Palavras-chave: Banhados; Bactérias heterotróficas; Coliformes; 16S rRNA.

\section{Microbiological water quality of the environmental preservation area: Fazenda Guajuviras - Canoas (RS)}

\begin{abstract}
Wetlands comprise several ecosystems, including wetlands, which are strategic places for conservation due to their high biological diversity and productivity resulting from the relationships established between water, soil, vegetation and fauna. Fazenda Guajuviras Environmental Protection Area (APA) is located in the municipality of Canoas (RS) and comprises about 560ha. The objective of this study was to analyze the contamination levels by heterotrophic bacteria and coliform group, to trace the biochemical profile and to identify some bacterial isolates present in two APA Guajuviras baths. To this end, the collections were performed in March 2015, and each bath was divided into four quadrants, from which $250 \mathrm{~mL}$ of water samples were collected. Wetland 2 presented the highest levels for both total and thermotolerant coliforms. In the quantification of heterotrophic bacteria, the highest levels found were in the northern quadrant of plated 1 and 2 . Eight bacterial strains were isolated from these plated. From the bacterial strains obtained from these baths, it was possible to identify, by sequencing the $16 \mathrm{~S}$ rRNA gene, eight isolates of two genera: Pseudomonas sp. and Serratia sp., and three other species: Bacillus subtilis, Lactococcus garvieae and Pseudomonas fluorescens.
\end{abstract}

Keywords: Plated; Heterotrophic bacteria; Coliforms; 16S rRNA.

Topic: Microbiologia

Reviewed anonymously in the process of blind peer.

Priscila Ribeiro Jankoski

Universidade Federal do Rio Grande do Sul, Brasil

http://lattes.cnpq.br/5095835950148273

priscilajankoski@gmail.com

Mateus de Oliveira Negreiros

Universidade Federal do Rio Grande do Sul, Brasil

http://lattes.cnpq.br/1648847359817283

mateuscamboimdeoliveira@yahoo.com.br

\section{Anelise Beneduzi da Silveira}

Universidade Federal do Rio Grande do Sul, Brasil

http://lattes.cnpq.br/1657893561568985

anelise.silveira@unilasalle.edu.br

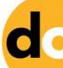

DOI: 10.6008/CBPC2318-2881.2018.002.0002
Received: 16/07/2018

Approved: 28/09/2018

Francisco Fernando de Castilho Koller

Universidade Federal do Rio Grande do Sul, Brasil

http://lattes.cnpq.br/3877374379218867

fckoller@gmail.com
Referencing this:

JANKOSKI, P. R.; NEGREIROS, M. O.; SILVEIRA, A. B.; KOLLER, F. F. C.. Qualidade microbiológica da água da área de preservação ambiental: Fazenda Guajuviras - Canoas (RS). Nature and Conservation, v.11, n.2, p.13-21, 2018. DOI: http://doi.org/10.6008/CBPC23182881.2018.002.0002 


\section{INTRODUÇÃO}

Os banhados, ou áreas úmidas, são regiões temporariamente ou permanentemente alagadas onde destaca-se a alta diversidade biológica existente, sendo considerados os ecossistemas mais produtivos do mundo (MALTCHIÊLK, 2003), e estão distribuídas em praticamente todas as regiões (JUNGBLUT et al., 2012). Esses ambientes abrigam uma variedade de espécies da flora e da fauna, e muitas comunidades microbianas (THATOI et al., 2013). As bactérias que habitam esses ecossistemas desempenham papéis ecológicos importantes, como nos ciclos biogeoquímicos, na degradação de contaminantes orgânicos e na distribuição de uma ampla gama de condições físicas e químicas em ambientes naturais (CONG et al., 2014; ZHANG et al., 2016).

De acordo com a Convenção de Ramsar, as áreas úmidas incluem 'áreas de pântanos, charco, turfa ou água, natural ou artificial, permanente ou temporária, com água estagnada ou corrente, doce, salobra ou salgada, incluindo áreas de água marítima com menos de seis metros de profundidade na maré baixa’. Além de regular o regime hídrico de vastas regiões, essas áreas funcionam como fonte de biodiversidade em todos os níveis tróficos, cumprindo também o papel relevante de caráter econômico, cultural e recreativo, e ao mesmo tempo atendendo às necessidades de água e alimentação para inúmeras espécies (BRASIL, 1996).

As áreas úmidas fornecem serviços ecossistêmicos vitais, retendo grandes volumes de água, dos quais os humanos dependem fortemente e se expõem. Ao mesmo tempo, as áreas úmidas fornecem aos ambientes aquáticos as condições ideais para a sobrevivência de certas bactérias, protozoários, vírus e helmintos, bem como seus hospedeiros, reservatórios e vetores (COOLS et al., 2013).

A contaminação de corpos hídricos naturais por microrganismos patogênicos tornou-se um problema de saúde pública mundial (KELLER et al., 2013). Muitos patógenos entéricos podem sobreviver no meio ambiente por semanas, seja na coluna d'água ou adsorvidos em partículas, e podem se acumular nos sedimentos.

As bactérias indicadoras fecais são o principal indicador da qualidade da água (SAVICHTCHEVA et al., 2006), e a principal representante de contaminação fecal na água é a bactéria Escherichia coli. Embora a grande maioria das estirpes de $E$. coli não sejam patogênicas, alguns estudos epidemiológicos relataram uma forte correlação entre as densidades de Escherichia coli na água e o risco de doença gastrointestinal (CABELLI et al., 1982; WIEDENMANN et al., 2005; MARION et al., 2010), fornecendo suporte para o uso desta bactéria como um indicador de contaminação fecal em sistemas de água doce.

A Área de Proteção Ambiental (APA) Fazenda Guajuviras está localizada no município de Canoas (RS) e compreende cerca de 560ha, onde se localizam diferentes ambientes naturais e antrópicos (FORNECK, 2011). O objetivo desse estudo foi analisar a qualidade ambiental da água quanto aos níveis de contaminação por bactérias heterotróficas e do grupo coliforme, traçar o perfil bioquímico e identificar os isolados bacterianos presentes em dois banhados da APA Fazenda Guajuviras Canoas (RS). 


\section{MATERIAIS E MÉTODOS}

\section{Área de estudo}

As coletas foram realizadas em dois banhados da APA Fazenda Guajuviras em março de 2015, localizada no município de Canoas (figura 1). Cada banhado foi dividido em quatro quadrantes (norte, sul, leste e oeste), de onde foram coletadas amostras de $250 \mathrm{~mL}$ de água, à profundidade de $30 \mathrm{~cm}$ da superfície, em frascos de cor âmbar, previamente esterilizados e identificados, totalizando oito amostras. As amostras, devidamente identificadas, foram conduzidas sob refrigeração até o Laboratório de Microbiologia da Universidade LaSalle, onde foram imediatamente processadas.

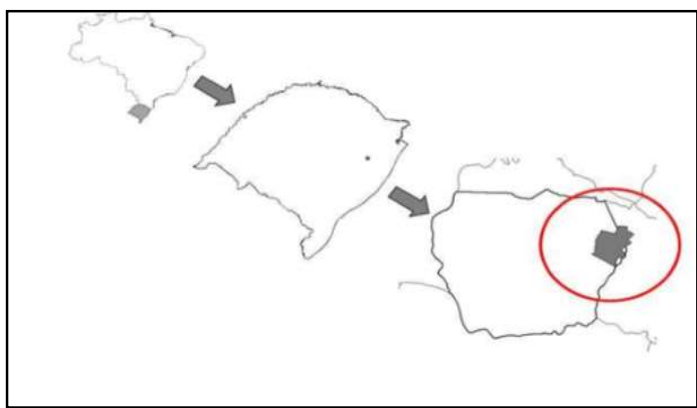

Figura 1: Localização da APA Fazenda Guajuviras no município de Canoas (RS).

\section{Coliformes totais e termotolerantes}

A partir de cada amostra bruta, foram feitas diluições seriadas até a diluição $10^{-5}$. Para a quantificação de coliformes totais e termotolerantes, foi utilizada a técnica do Número Mais Provável (NMP), onde foi aplicado $1 \mathrm{~mL}$ de cada diluição em 5 séries de 5 tubos contendo $9 \mathrm{~mL}$ do substrato cromogênico (Colilert ${ }^{\circledR}$ ). Esses tubos foram incubados por $24 \mathrm{~h}$ a $35^{\circ} \mathrm{C}$ em banho Maria. Os tubos com mudança da cor original para amarelo foram considerados positivos para coliformes totais. Para a confirmação dos coliformes termotolerantes, os tubos positivos foram submetidos à luz ultravioleta sendo considerados positivos aqueles com emissão de fluorescência. Os resultados dessas diluições foram avaliados através de combinações de contagem de tubos com resultado positivo e comparação com a tabela de Número Mais Provável (NMP).

\section{Bactérias heterotróficas}

Para a quantificação de bactérias heterotróficas, placas contendo Ágar Padrão para Contagem (Plate Count Agar- PCA) foram divididas em oito setores onde foram aplicadas alíquotas de $30 \mu \mathrm{L}$ de cada diluição, pela técnica de Dropplate, conforme Hoben et al. (1982), com quatro repetições, as placas foram incubadas a $35^{\circ} \mathrm{C}$ por $24 \mathrm{~h}$. Para obtenção dos isolados bacterianos, foi utilizado o meio não seletivo Ágar Infusão de Cérebro e Coração (Brain Heart Infusion- BHI) e aleatoriamente foram escolhidas algumas colônias que apresentaram diferentes morfotipos e estocadas em placas a $4^{\circ} \mathrm{C}$.

Com o objetivo de traçar o perfil bioquímico da comunidade bacteriana heterotrófica presente nos dois banhados, os isolados foram submetidos a provas bioquímicas a partir do cultivo nos seguintes meios 
de cultura: caldo lactosado, caldo verde brilhante, ágar citrato, ágar DNAse, ágar eosina azul de metileno (EMB), ágar MacConkey, meio SIM, caldo uréia, ágar vermelho violeta, ágar verde brilhante, ágar xilose lisina desoxicolato (XLD) e ágar ferro tríplice açúcar (TSI). Os isolados bacterianos foram inoculados nos respectivos meios de cultura e incubados de acordo com as recomendações dos fabricantes.

\section{Extração do DNA total e amplificação do fragmento do gene 16S rRNA}

Os isolados bacterianos foram lavados com tampão TES (Tris pH $8.010 \mathrm{mM}$, EDTA 25mM, NaCl), e ressuspendidos em tampão TE (Tris pH $8.010 \mathrm{mM}$, EDTA $25 \mathrm{mM}$ ). A lise celular foi realizada com lisozima $20 \mathrm{mg} \mathrm{ml}-1$ a $37^{\circ} \mathrm{C}$ e sódio dodecil-sulfato $4 \%$. As extrações foram feitas com fenol/clorofórmio, seguida de precipitação com etanol como descrito por Sambrook et al. (2001). A qualidade e integridade do DNA foram verificadas por eletroforese em gel de agarose $0,8 \%$. Um fragmento do gene $16 \mathrm{~S}$ rRNA foi amplificado das amostras em um termociclador Veriti 96 ThermalCycler (ApliedBiosystem) em 25ul de reação contendo $0,1 \mathrm{mM}$ de cada primer, $1 \mathrm{mM} \mathrm{MgCl} 2$ (Invitrogen), $10 \mathrm{mM}$ de cadadNTP (AmershamBiosciences) e $1 \mathrm{U}$ Taq DNA polimerase (Invitrogen).

A sequência do gene $16 \mathrm{~S}$ rRNA quase completa (1500pb) foi amplificada utilizando os primers 5'AGA GTT TGA TCC TGG CTC AG 3' (STACKEBRANDT et al., 1993) e 5'AGA AAG GAG GTG ATC CAG CC 3' (EDWARDS et al., 1989). As reações foram realizadas com um ciclo inicial de desnaturação a $94^{\circ} \mathrm{C}$ por $5 \mathrm{~min}$, seguido por 30 ciclos de amplificação, sendo cada ciclo composto por: 1 fase de desnaturação com duração de 1 min a $94^{\circ} \mathrm{C}, 1$ fase de anelamento de $1 \mathrm{~min}$ a $49^{\circ} \mathrm{C}$ e uma fase de extensão de $1 \mathrm{~min}$ a $72^{\circ} \mathrm{C}$. A extensão final foi de um ciclo a $72^{\circ} \mathrm{C}$ por $5 \mathrm{~min}$. Os produtos da PCR foram analisados em gel de agarose $1 \%$ corado com Blue Green LoadingDye I (LGC biotecnologia).

Os fragmentos obtidos dos isolados bacterianos foram sequenciados em uma orientação no laboratório ACTGene do Centro de Biotecnologia da UFRGS no sequenciador automático ABI-PRISM 3500 GeneticAnalyzer (AppliedBiosystems). As sequências obtidas foram comparadas com as disponíveis no banco de dados GenBank através do programa BLASTN (National Center for Biotechnology Information. As sequências de oito isolados bacterianos obtidos neste estudo foram depositadas no banco de dados com os números de acesso MG978193 a MG978200.

\section{Construção do dendrograma}

Para a análise do perfil bioquímico, uma matriz binária foi construída onde 0 indicou a ausência do perfil e 1 a presença. A similaridade/dissimilaridade bioquímica entre os isolados foi medida pelo coeficiente de Jaccard, o qual não considera as similaridades negativas. A matriz foi analisada pelo programa PAST (Paleontological Statistics) e o dendrograma obtido pelo método UPGMA (Unweighted Pair Group Method with Arithmetic Averages) (HAMMER et al., 2001). 


\section{DISCUSSÃO TEÓRICA}

A análise do índice de coliformes realizada pela técnica do número mais provável (NMP), evidenciou que a amostra coletada no quadrante sul do banhado 1 superou os demais quadrantes tanto na contaminação de coliformes totais (>1600NMP/100mL), quanto termotolerantes (17NMP/100mL), conforme mostrado na tabela 1 . No banhado 2 , os maiores índices para coliformes totais foram constatados nas amostras dos quadrantes norte e leste, (NMP >1600/100mL). Com relação aos coliformes termotolerantes o maior índice foi verificado na amostra do quadrante leste (600NMP/100mL), conforme a tabela 1.

Tabela 1: Contagem de coliformes totais e termotolerantes nos banhados 1 e 2 da APA Fazenda Guajuviras.

\begin{tabular}{|l|c|c|}
\hline Quadrante & $\begin{array}{c}\text { Coliformes Totais } \\
\text { (NMP/100ml) }\end{array}$ & Coliformes Termotolerantes (NMP/100mI) \\
\hline Banhado 1 Norte & 350 & 11 \\
\hline Banhado 1 Sul & $>1600$ & 17 \\
\hline Banhado 1 Leste & 41 & 6 \\
\hline Banhado 1 Oeste & 600 & 11 \\
\hline Banhado 2 Norte & $>1600$ & 6 \\
\hline Banhado 2 Sul & 600 & 7 \\
\hline Banhado 2 Leste & $>1600$ & 600 \\
\hline Banhado 2 Oeste & 250 & 6 \\
\hline
\end{tabular}

\section{Contagem de bactérias heterotróficas}

Os resultados obtidos a partir do cultivo em PCA revelaram que ambos banhados apresentaram os valores mais elevados de bactérias heterotróficas no quadrante norte do banhado $1\left(5,7 \times 10^{3}\right)$ e banhado 2 $\left(3 \times 10^{3}\right)$ e os menores no oeste do banhado $1\left(6,5 \times 10^{2}\right)$ e do banhado $2\left(1,6 \times 10^{3}\right)$, conforme a tabela 2 . No banhado 2 foi observada maior regularidade na distribuição de bactérias heterotróficas entre os quadrantes, em relação ao banhado 1. Esses resultados apontaram pouca variação entre os banhados, a exceção do quadrante oeste do banhado 1 . Apesar dos resultados indicarem que os maiores índices de coliformes tenham sido encontrados no quadrante sul, a contagem de heterotróficos foi mais expressiva no quadrante norte, sendo o sul o quadrante onde foi verificado o segundo menor índice de heterotróficos.

Tabela 2: Contagem de bactérias heterotróficas nos banhados 1 e 2 da APA Fazenda Guajuviras.

\begin{tabular}{|c|c|}
\hline Quadrante & UFC/mL \\
\hline Banhado 1 Norte & $5,7 \times 10^{3}$ \\
\hline Banhado 1 Sul & $1,1 \times 10^{3}$ \\
\hline Banhado 1 Leste & $2,3 \times 10^{3}$ \\
\hline Banhado 1 Oeste & $6,5 \times 10^{2}$ \\
\hline Banhado 2 Norte & $3 \times 10^{3}$ \\
\hline Banhado 2 Sul & $2 \times 10^{3}$ \\
\hline Banhado 2 Leste & $1,8 \times 10^{3}$ \\
\hline Banhado 2 Oeste & $1,6 \times 10^{3}$ \\
\hline
\end{tabular}

\section{Isolamento das colônias e perfil bioquímico dos isolados bacterianos selecionados}

A partir do crescimento de colônias no meio BHI, foram escolhidas aleatoriamente as que apresentaram diferentes morfotipos. Foram obtidos vinte e seis isolados no total, sendo treze caracterizados como Gram negativos e treze como Gram positivos. Os resultados dos testes bioquímicos dos isolados 
provenientes dos dois banhados investigados foram utilizados para a construção do dendrograma de similaridade de Jaccard (figura 2).

No dendrograma podemos observar a formação de dois grandes grupos, um reunindo os isolados $1 \mathrm{~N} 1,1 \mathrm{~N} 2,1 \mathrm{~N} 3,1 \mathrm{~S} 1,1 \mathrm{~S} 2,2 \mathrm{~L} 2$, $2 \mathrm{~L} 3$ e 201 e outro formado por 1L4, 1L1, 2N2, 2S2, 202, 1L5, 1L6, 2S1, 103, 2N1, 1L2, 1S3, 1S4 e 1L3. Enquanto os isolados 2L1, 101, 102 e 1N4 apresentaram baixa similaridade em relação aos dois grandes grupos. Os maiores índices de similaridade foram verificados entre $1 \mathrm{~N} 1$ e $1 \mathrm{~N} 2$, $1 \mathrm{~L} 5$ e $1 \mathrm{~L} 6$ (100\%).

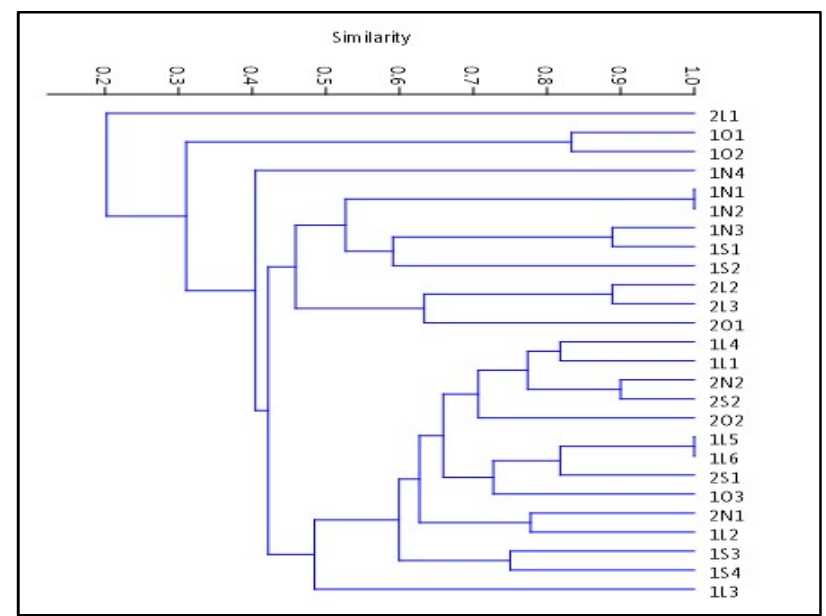

Figura 2: Dendrograma do perfil bioquímico dos isolados bacterianos obtidos dos banhados da APA Fazenda Guajuviras.

\section{Identificação da espécie e/ou gênero a que pertencem os isolados}

A partir do sequenciamento foi possível a identificação de oito isolados de três gêneros: Bacillus sp., Pseudomonas sp. e Serratia sp., e de mais três espécies: Bacillus subtilis, Lactococcus garvieae e Pseudomonas fluorescens. Dessas oito bactérias identificadas, sete eram provenientes do banhado 1, e apenas uma do banhado 2. Pseudomonas fluorescens foi encontrada no banhado 1 e 2, como consta na tabela 3.

Tabela 3: Identificação dos isolados bacterianos obtidos dos banhados da APA Fazenda Guajuviras.

\begin{tabular}{|c|c|}
\hline Isolado & Identificação \\
\hline $1 \mathrm{~L} 1$ & Bacillus subtilis \\
\hline $1 \mathrm{~L} 4$ & Bacillus sp. \\
\hline $1 \mathrm{~L} 6$ & Serratia sp. \\
\hline $1 \mathrm{~N} 2$ & Pseudomonas fluorescens \\
\hline $1 \mathrm{~N} 4$ & Pseudomonas sp. \\
\hline $1 \mathrm{~S} 3$ & Lactococcus garvieae \\
\hline $1 \mathrm{~S} 4$ & Lactococcus garvieae \\
\hline $2 \mathrm{~S} 1$ & Pseudomonas fluorescens \\
\hline
\end{tabular}

A análise e monitoramento da qualidade microbiológica dos ecossistemas aquáticos ajuda a entender o impacto e as consequências da contaminação ambiental (KELLER et al., 2013). Neste estudo foi constatada a contaminação por coliformes totais e termotolerantes em todos os pontos coletados dos banhados da APA Guajuviras. O banhado 1 era localizado nas proximidades da entrada da APA, com a presença de cavalos e animais domésticos, esperava-se que esse banhado apresentasse os maiores índices de contaminação por bactérias do grupo coliforme. Enquanto o banhado 2 por estar localizado em uma área de acesso dificultado 
devido ao fato de encontrar-se em meio à vegetação arbórea em recuperação, a expectativa era que esse banhado apresentasse os menores índices de contaminação bacteriana.

De acordo com Ringuelet (1962), os banhados são definidos como "corpos d'água permanentes ou temporários, sem uma bacia bem definida, de contorno ou perímetro indefinido e sem sedimentos próprios, apresentando vegetação emergente abundante e poucos espaços livres. Ainda, podem formar uma paisagem em mosaico, contendo vários outros habitats em seu interior, sendo considerado macro-habitats".

Desse modo fatores como a incidência solar, a chuva e a vegetação podem ter favorecido a formação de microambientes, que de alguma forma pode ter influenciado os resultados de coliformes totais e termotolerantes. Nesse caso, o banhado 2 apresentou os valores maiores de contaminação por coliformes totais e termotolerantes. Nossos resultados contrariam os referidos por Martins (2013) que ao analisar os dois banhados da APA Fazenda Guajuviras relatou maior contaminação por bactérias do grupo coliforme no banhado 1.

Dessa forma reforçando a possibilidade de outros fatores que não a presença de animais de criação, como principais responsáveis pela contaminação. Ghaderpour et al. (2014) analisou o nível de bactérias indicadoras fecais e a presença de bactérias potencialmente patogênicas em águas superficiais e sedimento de uma área úmida na Malásia. Foram detectados coliformes totais e a bactéria Escherichia coli na superfície da água de todos os locais amostrados.

Em relação ao perfil bioquímico das bactérias podemos observar que embora os isolados não tenham formado ou constituído agrupamentos distintos para cada banhado, os maiores índices de similaridade foram obtidos entre isolados de um mesmo banhado, com tendência de agrupamento por quadrante $(101,102$, 1N1, 1N2, 2L2, 2L3, 1L4, 1L1, 1L5, 1L6, 1S3 e 1S4). Podemos destacar também uma ligeira tendência dos isolados bacterianos provenientes do sul e norte (1N3, 1S1, 2N2 e 2S2) em apresentarem elevados índices de similaridade com mais de $85 \%$. Apesar do isolado $2 \mathrm{~L} 1$ ter apresentado o menor índice de similaridade dos demais, observou-se uma pequena tendência de agrupamento entre os isolados do quadrante leste (2L2, $2 L 3,1 L 4,1 L 1,1 L 5$ e $1 L 6)$. Enquanto $o$ isolado do quadrante oeste se mostrou com um comportamento distinto dos demais.

No presente estudo, foram identificados entre os isolados bacterianos três gêneros distintos, são eles: Bacillus sp., Pseudomonas sp. e Serratia sp., e três espécies: Bacillus subtilis, Lactococcus garvieae e Pseudomonas fluorescens. As bactérias do gênero Bacillus sp. são geralmente saprófitas, e não patogênicas para os animais. O habitat principal desses micro-organismos é o solo, onde muitas espécies são secretoras de metabólitos secundários (SANSINEA et al., 2016). Lactococcus garviae é responsável por septicemia hiperaguda e hemorrágica em peixes, ele foi um dos patógenos aquáticos mais graves, causando grandes perdas econômicas tanto em animais aquáticos selvagens quanto em animais de criação em todo o mundo (VENDRELL et al., 2006).

Pseudomonas fluorescens é uma bactéria Gram-negativa, em forma de bastonete, e é amplamente distribuída na natureza incluindo solo, água e plantas (XIANG et al., 2018). Os resultados do presente estudo 
indicam que as águas da APA Guajuviras estão contaminadas com algumas bactérias potencialmente patogênicas, podendo levar à contaminação de peixes e outros vertebrados que habitam nesses ambientes.

\section{CONCLUSÕES}

Os resultados indicaram a contaminação por coliformes totais e termotolerantes nos oito pontos analisados dos banhados da APA Fazenda Guajuviras, e também uma alta densidade de bactérias heterotróficas, com exceção do quadrante oeste do banhado 1. Os maiores índices de contaminação tanto por coliformes totais e termotolerantes foram verificados no banhado 2 . No estudo foi possível a identificação de três gêneros distintos nas áreas de banhado Bacillus sp., Pseudomonas sp. e de Serratia sp. e de mais três espécies: Bacillus subtilis, Lactococcus garvieae e Pseudomonas fluorescens.

\section{REFERÊNCIAS}

BRASIL. Decreto n.1905 de 16 de maio de 1996. Promulga a Convenção sobre Zonas Úmidas de Importância Internacional, especialmente como habitat de aves aquáticas, conhecida como Convenção de Ramsar. Brasília: DOU, 1996.

CABELLI, V. J.; DUFOUR, A. P.; MCCABE, L. J.; LEVIN, M. A.. Swimming-associated gastroenteritis and water quality. American Journal of Epidemiology, Oxford, v.115, n.4, p.606-616, 1982. DOI:

https://doi.org/10.1093/oxfordjournals.aje.a113342

CONG, M.; CAO, D.; SUN, J.; SHI, F.. Soil microbial community structure evolution along halophyte succession in Bohai Bay wetland. Journal of Chemistry, Cairo, 2014. DOI:

http://doi.org/10.1155/2014/491347

COOLS, J.; DIALLO, M.; BOELLE, E.; LIERSCH, S.; COERTJENS, D.; VANDENBERGHE, V.; KONE, B.. Integrating human health into wetland management for the Inner Niger Delta, Mali. Environmental Science \& Policy, Amsterdam, v.34, p.34-43, 2013. DOI: https://doi.org/10.1016/i.envsci.2012.09.011

EDWARDS, U.; ROGALL, T.; BLOCKERL, H.; EMDE, M.; BOTTGER, E. C.. Isolation and direct complete nucleotide determination of entire genes. Characterization of a gene coding for $16 \mathrm{~S}$ ribosomal RNA. Nucleic Acids Research, Oxford, v. 17 p. 7843-7853, 1989. DOI:

https://doi.org/10.1093/nar/17.19.7843

GHADERPOUR, A.; NASORI, K. N. M.; CHEW, L. L.; CHONG, V. C.; THONG, K. L.; CHAI, L. C.. Detection of multiple potentially pathogenic bacteria in Matang mangrove estuaries, Malaysia. Marine Pollution Bulletin, Amsterdam, v.83, n.1, p.324-330, 2014. DOI:

https://doi.org/10.1016/i.marpolbul.2014.04.029

HAMMER, O.; HARPER, D. A. T.; RYAN, P. D.. PAST: Paleontological Statistics Software Package for Education and Data Analysis. Palaeontologia Electronica, n.4, 2001.

HOBEN, H. J.; SOMASEGARAN, P.. Comparison of the pour, spread, and drop plate methods for enumeration of Rhizobium spp. in inoculants made from presterilized peat. Applied and Environmental Microbiology, Washington, v.44, p.1246-1247, 1982.
JUNGBLUT, A. D.; WOOD, S. A.; HAWES, I.; WEBSTERBROWN, J.; HARRIS, C.. The Pyramid Trough Wetland: environmental and biological diversity in a newly created Antarctic protected area. FEMS Microbiology Ecology, Oxford, v.82, n.2, p.356-366, 2012. DOI: https://doi.org/10.1111/j.1574-6941.2012.01380.x

KELLER, R.; JUSTINO, J. F.; CASSINI, S. T.. Assessment of water and seafood microbiology quality in a mangrove region in Vitória, Brazil. Journal of Water and Health, Londres, v.11, n.3, p.573-580, 2013. DOI: https://doi.org/10.2166/wh.2013.245

MALTCHIÊK, L.; ROLON, A. S.; GROTH, C.. Diversidade de macrófitas aquáticas em áreas úmidas da Bacia do Rio dos Sinos, Rio Grande do Sul. Pesquisas: Botânica, São Leopoldo, v.52, p.143-154, 2002.

MARION, J. W.; LEE, J.; LEMESHOW, S.; BUUCKLEY, T. J.. Association of gastrointestinal illness and recreational water exposure at and inland US beach. Water Research, Amsterdam, v.44, n.16, p.4796-4804, 2010. DOI: https://doi.org/10.1016/i.watres.2010.07.065

MARTINS, S. H.. Bactérias do grupo coliforme e macroinvertebrados bentônicos como bioindicadores em corpos d'água da APA Guajuviras em Canoas (RS). Monografia (Graduação em Ciências Biológicas) Universidade La Salle, Canoas, 2013.

RINGUELET, R. A.. Ecologia acuática continental. Buenos Aires: EUDEBA, 1962.

SAMBROOK, J.; RUSSEL, D. W.. Molecular Cloning: a laboratory manual. Nova York: Cold Spring Harbor Laboratory Press, 2001.

SANSINEA, E.; SALAZAR, F.; JIMÉNEZ, J.; MENDOZA, A.; ORTIZ, A.. Diketopoperazines derivates isolated from Bacillus thuringiensis and Bacillus endophyticus, establishment of their configuration by X-ray and their synthesis. Tetrahedron Letters, Amsterdam, v.57, p.2604-2607, 2016. DOI: https://doi.org/10.1016/i.tetlet.2016.04.117 
SAVICHTCHEVA, O.; OKABE S.. Alternative indicators of fecal pollution: Relations with pathogens and conventional indicators, current methodologies for direct pathogen monitoring and future application perspectives. Water Research, Amsterdam, v.40, n.13 p.2463-2476, 2006. DOI: https://doi.org/10.1016/j.watres.2006.04.040

STACKEBRANDT, E.; LIESACK, W.. Nucleic acids and classification. In: GOODFELLOW, M.; O'DONNELL, A. G.. Handbook of New Bacterial Systematics. London: Academic Press, 1993. p.152-189.

THATOI, H.; BEHERA, B. C.; MISHRA, R. R.; DUTTA, S. K.. Biodiversity and biotechnological potential of microorganisms from mangrove ecosystems: a review. Annals of Microbiology, Basileia, v.63, n.1, p.1-19, 2013. DOI: https://doi.org/10.1007/s13213-012-0442-7

VENDRELL, D.; BALCÁZAR, J. L.; RUIZ-ZARZUELA, I.; BLAS, I.; GIRONÉS, O.; MÚZQUIZ, J. L.. Lactococcus garvieae in fish: a review. Comparative Immunology, Microbiology and
Infectious Diseases, Amsterdam, v.29, n.4, p.177-198, 2006. DOI: https://doi.org/10.1016/j.cimid.2006.06.003

WIEDENMANN, A.; KRUGER, P.; DIETZ, K.; LOPES-PILA, J. M.; SZEWZYK, R.; BOTZENHART, K.. A randomized controlled trial assessing infectious disease risks from bathing in fresh recreational waters in relation to the concentration of Escherichia coli, intestinal Enterococci, Clostridium perfringens, and somatic coliphages. Environmental Health Perspectives, Durham, v.114, n.2, p.228-236, 2005.

XIANG, Y.; WANG, S.; LI, J.; WEI, Y.; ZHANG, Q.; LIN, L.; JI, X.. Isolation and characterization of two lytic coldactive bacteriophages infecting Pseudomonas fluorescens from the Napahai plateau wetland. Canadian Journal of

Microbiology, Ottawa, v.64, n.3, p.183-190, 2017. DOI: https://doi.org/10.1139/cjm-2017-0572

ZHANG, B. C.; KONG, W. D.; WU, N.; ZHANG, Y. M.. Bacterial diversity and community along the succession of biological soil crusts in the Gurbantunggut Desert, Northern China. Journal of Basic Microbiology, Hoboken, v.56, n.6, p.670679, 2016. DOI: https://doi.org/10.1002/jobm.201500751

A CBPC - Companhia Brasileira de Produção Científica (CNPJ: 11.221.422/0001-03) detém os direitos materiais desta publicação. Os direitos referem-se à publicação do trabalho em qualquer parte do mundo, incluindo os direitos às renovações, expansões e disseminações da contribuição, bem como outros direitos subsidiários. Todos os trabalhos publicados eletronicamente poderão posteriormente ser publicados em coletâneas impressas sob coordenação da Sustenere Publishing, da Companhia Brasileira de Produção Científica e seus parceiros autorizados. Os (as) autores (as) preservam os direitos autorais, mas não têm permissão para a publicação da contribuição em outro meio, impresso ou digital, em português ou em tradução. 